\title{
Bouvaist Cubic of a Triangle in an Isotropic Plane
}

\section{Bouvaist Cubic of a Triangle in an Isotropic Plane ABSTRACT \\ The cubic in an isotropic plane which passes through the intersections of the sides of an orthic triangle with the sides of a complementary triangle of a given triangle, and through the point which is complementary to the Steiner point of triangle is studied in this paper. It is proved that its non-isotropic asymptote is parallel to Lemoine line of a given triangle.}

Key words: isotropic plane, Bouvaist cubic, point complementary to the Steiner point

MSC2010: 51N25
In [1], Bouvaist showed the existence of a cubic in Euclidean geometry, which passes through all nine intersections of the sides of an orthic triangle and a complementary triangle of a given triangle and through a point complementary to the Steiner point of that triangle. He proved that this cubic is circular and its real asymptote is parallel to the Lemoine line of a given triangle.

It will be shown in this paper that some analogous statement holds in the isotropic plane as well.

The isotropic (or Galilean) plane is a projective-metric plane, where the absolute consists of one line, i.e., the absolute line $\omega$, and one point on that line, i.e., the absolute point $\Omega$. The lines through the point $\Omega$ are isotropic lines, and the points on the line $\omega$ are isotropic points (the points at infinity). Two points $P_{1}=\left(x_{1}, y_{1}\right), P_{2}=\left(x_{2}, y_{2}\right)$ with $x_{1}=x_{2}$ are said to be parallel, and we shall say they are on the same isotropic line. Any isotropic line is perpendicular to any non-isotropic line.

\section{Bouvaistova kubika trokuta u izotropnoj ravnini}

\section{SAŽETAK}

U članku se proučava kubika koja prolazi kroz sjecišta stranica ortotrokuta i komplementarnog trokuta danog trokuta i kroz točku komplementarnu Steinerovoj točki tog trokuta. Dokazuje se da je neizotropna asimptota kubike paralelna s Lemoineovim pravcem danog trokuta.

Ključne riječi: izotropna ravnina, Bouvaistova kubika, komplementarna točka Steinerovoj točki

A triangle is said to be allowable if none of its sides is isotropic. Each allowable triangle $\mathrm{ABC}$ can be set by a suitable choice of the coordinate system in the standard position, in which its circumscribed circle has the equation $y=x^{2}$, and its vertices are the points $A=\left(a, a^{2}\right), \quad B=$ $\left(b, b^{2}\right), \quad C=\left(c, c^{2}\right)$, where $a+b+c=0$. We shall say then that $A B C$ is a standard triangle. To prove geometric facts for each allowable triangle it is sufficient to give a proof for the standard triangle (see [3]).

With the labels

$p=a b c \quad$ and $\quad q=b c+c a+a b$

a number of useful equalities are proved in [3], as e.g.

$$
\begin{aligned}
a^{2} & =b c-q, \\
(b-c)^{2} & =-(q+3 b c), \\
(c-a)(a-b) & =2 q-3 b c .
\end{aligned}
$$

In [3], it is proved that the sides $B_{h} C_{h}$ and $B_{m} C_{m}$ of the orthic triangle $A_{h} B_{h} C_{h}$ and the complementary triangle 
$A_{m} B_{m} C_{m}$ of the standard triangle have the equations:

$$
\begin{aligned}
y-2 a x+q-2 b c & =0, \\
y+a x+q-\frac{b c}{2} & =0,
\end{aligned}
$$

and the equations of their other sides are obtained by a cyclic permutation $a \rightarrow b \rightarrow c \rightarrow a$. That is why every cubic through all nine intersections of the sides of these two triangles has the equation of the form:

$$
\prod(y-2 a x+q-2 b c)-\lambda \prod\left(y+a x+q-\frac{b c}{2}\right)=0,
$$

where $\Pi$ denotes the product of three factors, the first of which is written, and the other two arise from the first one by cyclic permutations $a \rightarrow b \rightarrow c \rightarrow a$.

In [4], it is shown that the point

$$
S=\left(\frac{3 p}{2 q},-\frac{9 p^{2}}{2 q^{2}}-q\right)
$$

is complementary to the Steiner point of the standard triangle $A B C$. For that point we obtain

$$
\begin{aligned}
y & -2 a x+q-2 b c=-\frac{9 p^{2}}{2 q^{2}}-\frac{3 a p}{q}-2 b c \\
& =-\frac{b c}{2 q^{2}}\left(9 a^{2} b c+6 a^{2} q+4 q^{2}\right) \\
& =-\frac{b c}{2 q^{2}}\left[9 b c(b c-q)+6 q(b c-q)+4 q^{2}\right] \\
& =\frac{b c}{2 q^{2}}\left(2 q^{2}+3 b c q-9 b^{2} c^{2}\right) \\
& =\frac{b c}{2 q^{2}}(q+3 b c)(2 q-3 b c) \\
& =-\frac{b c}{2 q^{2}}(b-c)^{2}(c-a)(a-b), \\
y & +a x+q-\frac{b c}{2}=-\frac{9 p^{2}}{2 q^{2}}+\frac{3 a p}{2 q}-\frac{b c}{2} \\
& =-\frac{b c}{2 q^{2}}\left(9 a^{2} b c-3 a^{2} q+q^{2}\right) \\
& =-\frac{b c}{2 q^{2}}\left[9 b c(b c-q)-3 q(b c-q)+q^{2}\right] \\
& =-\frac{b c}{2 q^{2}}\left(4 q^{2}-12 b c q+9 b^{2} c^{2}\right), \\
& =-\frac{b c}{2 q^{2}}(2 q-3 b c)^{2} \\
& =-\frac{b c}{2 q^{2}}(c-a)^{2}(a-b)^{2} \\
&
\end{aligned}
$$

and then

$\prod(y-2 a x+q-2 b c)=-\frac{a^{2} b^{2} c^{2}}{8 q^{6}}(b-c)^{4}(c-a)^{4}(a-b)^{4}$, $\prod\left(y+a x+q-\frac{b c}{2}\right)=-\frac{a^{2} b^{2} c^{2}}{8 q^{6}}(b-c)^{4}(c-a)^{4}(a-b)^{4}$

Thus, the cubic of the pencil of the cubics with equation (1) passes through the point $S$ if one takes $\lambda=1$ (Figure 1).

If that cubic of the allowable triangle $A B C$, which passes through the intersections of the sides of its orthic triangle with the sides of its complementary triangle, and through the point $S$ complementary to the Steiner point of the triangle $A B C$ (Figure 1), is called the Bouvaist cubic of that triangle, then we have:

Theorem 1 The Bouvaist cubic $\mathcal{B}$ of the standard triangle $A B C$ has the equation:

$$
\begin{aligned}
& (y-2 a x+q-2 b c)(y-2 b x+q-2 c a) \\
& (y-2 c x+q-2 a b)-\left(y+a x+q-\frac{b c}{2}\right) \\
& \left(y+b x+q-\frac{c a}{2}\right)\left(y+c x+q-\frac{a b}{2}\right)=0 .
\end{aligned}
$$

Let us now find the intersection points of the cubic (2) and the absolute line. We have to solve the equation

$(y-2 a x)(y-2 b x)(y-2 c x)-(y+a x)(y+b x)(y+c x)=0$,

which can also be written in the following form:

$$
-3(a+b+c) x y^{2}+3(b c+c a+a b) x^{2} y-9 a b c x^{3}=0,
$$

and finally as $3 q x^{2} y-9 p x^{3}=0$. We have the double solution $x=0$ and the solution $y=\frac{3 p}{q} x$, which means that the cubic has an asymptote with a slope $\frac{3 p}{q}$, which is by [2] a slope of the Lemoine line $\mathcal{L}$ of the triangle $A B C$. We obtained:

Theorem 2 The non-isotropic asymptote of Bouvist cubic of an allowable triangle is parallel to the Lemoine line of a given triangle. Absolute point is an intersection point of the Bouvaist cubic and absolute line with intersection multiplicity 2. 


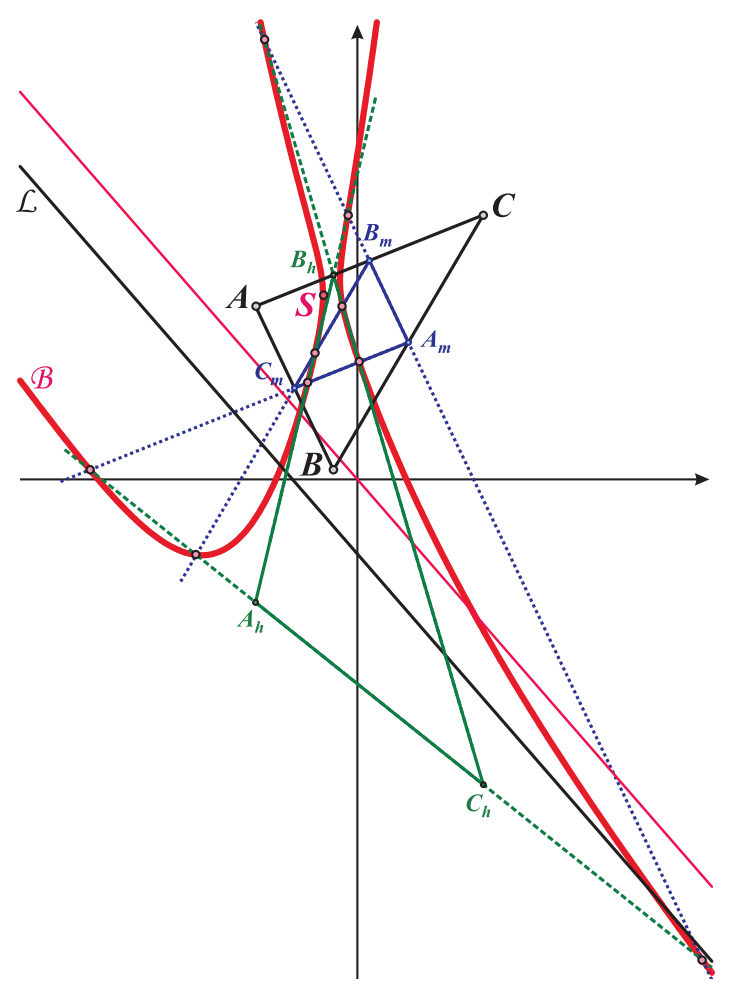

Figure 1: Bouvaist cubic of a triangle ABC in isotropic plane

\section{References}

[1] R. Bouvaist, Généralization de la question 2811, Mathesis 48 (1934), 451-452.

[2] Z. KOlAR-Begović, R. KOLAR-ŠUPER, J. BEBAN-BRKIĆ, V. VOLENEC, Symmedians and the symmedian centre of the triangle in an isotropic plane, Math. Pannon. 17 (2006), 287-301.

[3] R. KOLAR-ŠUPeR, Z. KOlAR-Begović, V. Volenec, J. BebAn-Brkić, Metrical relationships in a standard triangle in an isotropic plane, Math. Commun. 10 (2005), 149-157.

[4] R. KOLAR-ŠUPER, Z. KOLAR-BEGOVIĆ, V. VOLEnEC, Steiner point of a triangle in an isotropic plane, Rad Hrvat. Akad. Znan. Umjet. Mat. Znan. 20528 (2016), 83-95.

\section{Ružica Kolar-Šuper}

orcid.org/0000-0002-8945-2745

e-mail: rkolar@foozos.hr

Faculty of Education, University of Osijek

Cara Hadrijana 10, 31000 Osijek, Croatia 